\title{
Factors influencing the utilization of maternal health care services by nomads in Sudan
}

\author{
Babker El Shiekh ${ }^{1 *}$ and Anke van der Kwaak ${ }^{2}$
}

\begin{abstract}
Sudan has high maternal mortality. The rate among nomads - groups of people who move from place to place as a way of obtaining food, finding pasture or make a living - is very high and varies between different regions of the country. The objective of the study is to identify the factors affecting the utilization of maternal health care services by nomadic communities in Sudan, to make recommendations to improve their health. Nomadic health practices and health care services are the main influencing factors affecting the utilization of maternal health care services. Nomadic health practices are influenced by the mobile lifestyle of nomads, their low level of education and knowledge, gender norms, beliefs, values and attitudes, and their geographical locations. Existing health care services are ill-adapted to the nomadic lifestyle. The study also demonstrates some best practices from other countries that can be applied to the nomadic context in Sudan, such as community health workers, training and support for traditional birth attendants, provision of joint mobile health services for humans and livestock and the establishment of maternity or birth waiting homes. Since the utilization of maternal health care services by nomads is extremely low, the study recommends evidence-based strategies to increase community demand for services or bring women closer to emergency obstetric services.
\end{abstract}

Keywords: Maternal health, Nomads, Utilization, Sudan, Maternal mortality

\section{Background}

Nomads are groups of people who move from place to place as a way of obtaining food, finding pasture for livestock or otherwise make a living (Ahmed and Abdel-Rahman 2008). Most nomadic groups follow a fixed annual or seasonal pattern of movement and settlement. They often travel by animal or on foot, and they live in tents or portable shelters made out of tree branches or animal hides. In the context of the study about Sudan, the term 'nomads' is used to refer to a population that moves temporarily or permanently along with their animals as a way of living.

Globally, the current estimated number of nomads is uncertain because accurate statistical data are not available. This is probably caused by unclear definitions and vague boundaries between settled and mobile communities (Sheikh and Velema 1999). However, the population of nomads and semi-nomads across the world is estimated at 50 to 100 million

\footnotetext{
* Correspondence: babkeribra@gmail.com

1Jabra Taha Elmahi, Khartoum, Sudan

Full list of author information is available at the end of the article
}

(Maro et al. 2012). The majority of nomads (60\%) are found in Africa, where they face numerous challenges in accessing health care services compared to settled populations (Sheikh and Velema 1999; Maro et al. 2012).

Sudan has a large nomadic population, as $66 \%$ of the land in Sudan is arid and mostly pastoral (Casciarri and Ahmed 2009). According to the fifth census of 2008, the nomadic population in Sudan was estimated at 2,778,774 people (Figure 1). This represents $7.1 \%$ of the total population; however, this percentage is believed to be higher after the cession of South Sudan. The population structure of nomads is expansive (Figure 2), with young people constituting the largest proportion of the population. The nomadic population has increased significantly over recent decades (Table 1) (Casciarri and Ahmed 2009; Ali 2008). The fluctuating numbers of nomads can be explained by a number of reasons, such as:

- The numbers of nomads were miscalculated in previous statistics;

\section{倠 Springer}

(C) 2015 El Shiekh and Kwaak. Open Access This article is distributed under the terms of the Creative Commons Attribution 4.0 International License (http://creativecommons.org/licenses/by/4.0/), which permits unrestricted use, distribution, and reproduction in any medium, provided you give appropriate credit to the original author(s) and the source, provide a link to the Creative Commons license, and indicate if changes were made. 


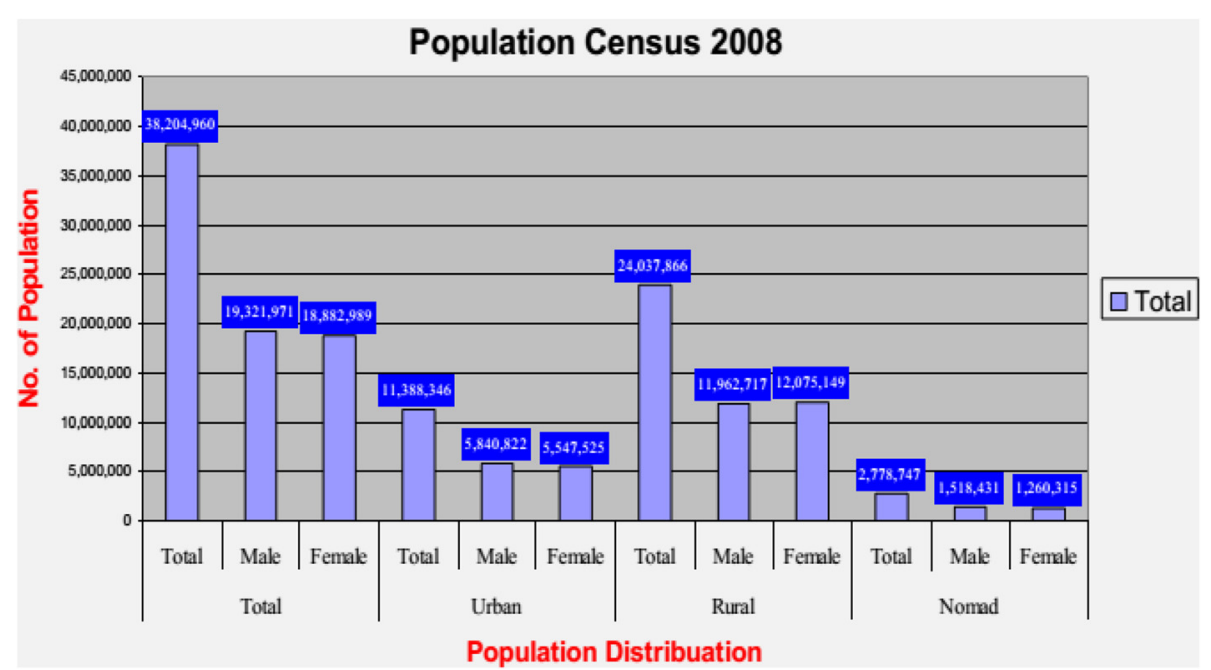

Figure 1 Nomadic population pyramid in Sudan, 2008

- Old statistics (e.g. censuses from 1983 and 1993) often relied on projections from previous statistics and previous growth rates, rather than actual numerations;

- Nomadic communities are reluctant to participate in the censuses for social and cultural reasons, they might seem to be afraid of evil eyes or they might not be willing to pay taxes on their animals (Ahmed and Abdel-Rahman 2008);

- Cross-border movement of nomads and definitions used by the Central Bureau of Statistics (Ali 2008); and

- Access to these tribes is difficult because of poor road conditions in Sudan (Ahmed and Abdel-Rahman 2008).

The nomads of Sudan are concentrated in the western part of the country, namely in Darfur and Kordofan regions. The state of South Darfur (now the states of South and East Darfur) has the bulk of the nomads (58.2
\%), while $19.6 \%$ live in the states of North and South Kordofan. There are about $16.1 \%$ in eastern Sudan in the states of Kassala and Red Sea. The remaining populations of nomads are spread over other states in smaller numbers (Ali 2008; Ahmed and Abdel-Rahman 2008).

Sudan has poor sexual and reproductive health indicators. The maternal mortality ratio (MMR) is estimated at 360 maternal deaths per 100,000 live births and has only decreased by $50 \%$ between 1990 and 2013 (WHO et al. 2014). The risk of adult women dying from pregnancyand childbirth-related causes is 1 in 60 (WHO et al. 2014). In 2013, the proportion of deliveries attended by trained personnel was about $30 \%$ (WHO 2014a). The proportion of institutional delivery is extremely low (20\%) because the common practice is home delivery, even in urban areas (Federal Ministry of Health 2011).

The maternal health status of nomads is even worse, as a census of Sudan in 2008 reveals very high maternal

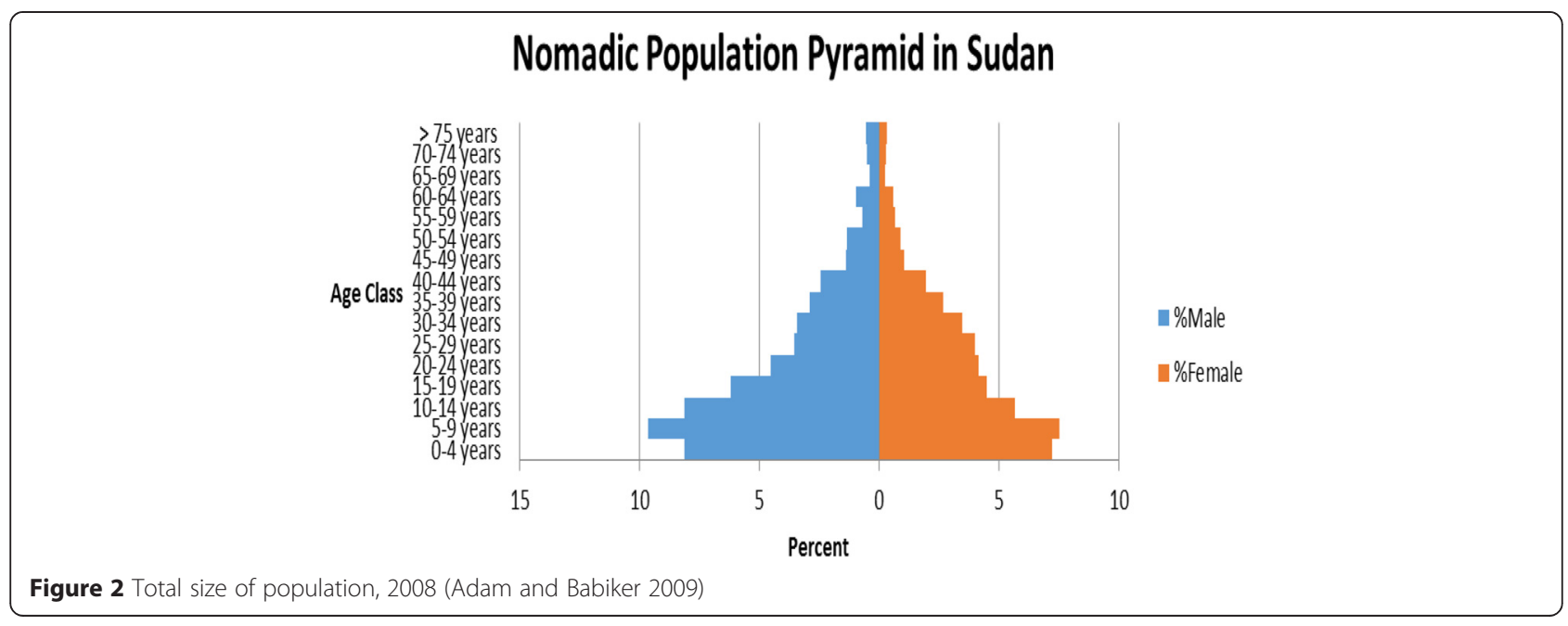


Table 1 Growth of the nomadic population in Sudan, 1973 to 2008 (Ahmed and Abdel-Rahman 2008)

\begin{tabular}{ll}
\hline Year & Population (1000s) \\
\hline 1973 & 1,630 \\
1983 & 2,265 \\
1993 & 696 \\
2008 & 2,779 \\
\hline
\end{tabular}

mortality among nomads. It is estimated that the MMR is as high as 503 maternal deaths per 100,000 live births (Alnoory 2008; Ahmed and Abdel-Rahman 2008). The high MMR among nomads is due to a number of reasons. Nomads encounter challenges in accessing and utilizing the services of trained midwives or other skilled maternal health service providers. The cultural beliefs of nomads, such as the number of children born in a family being a symbol of its position in the community, indicate little use of family planning methods (Montavon et al. 2013). This has a direct correlation to maternal mortality and morbidity, unless pregnancies are well spaced. Other cultural practices such as widespread practices of female genital mutilation (FGM) and early marriage are also contributing to high maternal mortality. In addition, other reasons for high maternal mortality include i) misconceptions and practices related to nutrition, maternal diet and maternal care; ii) limited access to health care services; and iii) low rates of enrolment in formal education (Schelling et al. 2003; Schelling et al. 2005; Montavon et al. 2013).

Given these statistics, there is a need to better understand the factors that influence the status of nomadic maternal health; therefore, this study focuses on maternal health among the nomadic communities of Sudan. It will analyse different factors that influence the utilization of maternal health care services by nomads, and, citing success from similar contexts, it will provide suggestions and recommendations to improve utilization.

\section{Study area}

Sudan covers an area of $1,882,000 \mathrm{~km}^{2}$ in the north-east of Africa between $15^{\circ} 00^{\prime} \mathrm{N}$ and $30^{\circ} 00^{\prime} \mathrm{E}$. Sudan borders Egypt, Libya, Chad, the Central Africa Republic, South Sudan, Ethiopia and Eretria (UNDP 2013). The total population of Sudan was estimated at 37,289,406 in 2014, with $63 \%$ of people living in rural areas (Sudan Central Bureau of Statistics 2013).

Geographically, the terrain of Sudan consists of flat plains and mountains. The Blue and White Niles meet at Khartoum to establish the great Nile river which runs towards the north before crossing the border with Egypt (Anon 2014). Sudan's climate consists of an arid zone in the north (Nubian Desert) as a continuation of the great desert, and a tropical zone in the south and south-west
(Anon 2014). The existence of different climates and the presence of the Red Sea and large numbers of mountains have led to variations in the density of rainfall, temperatures, types of soil and the topography. These factors play an important role in determining the types and distribution of plants and pasture. In addition, the availability of pastoral land is an important factor determining the distribution and location of different nomadic groups across the country.

\section{Methods}

\section{Study design}

This study is a literature review of published and unpublished studies, research and reports about the maternal health of nomads in Sudan. Because data about nomads in Sudan are limited, the author has searched and included articles from neighbouring countries. Google and Google Scholar were the main search engines used to find related articles, and other specific websites such as the World Health Organization (WHO), Federal Ministry of Health, Central Bureau of Statistics, World Bank, United Nations Population Fund (UNFPA) and United Nations Children Fund (UNICEF) were also used. Searching was also conducted through the library catalogue of PubMed and VU University Amsterdam. Some resources were extracted from KIT library publications.

\section{Conceptual framework of the study}

Andersen and Newman state that the utilization of health care services is always influenced by social determinants and individual behaviour (Andersen 1995). With similar concepts, other conceptual frameworks for analysing the utilization of health care services include Rosenstock's health belief model (Rosenstock 1974) and the Three Delays model for maternal mortality (Thaddeus and Maine 1994). Andersen's framework was chosen because it focuses on analysis of health service utilization from a socio-demographic perspective. Andersen's behavioural model of health care service use (Figure 3) theoretically assumes that certain characteristic factors contribute to or determine an individual's use of health care services. The model groups these factors into three categories: predisposing characteristics, enabling characteristics and need-based characteristics (Andersen 1995).

\section{Study limitations}

This study shows some limitations:

- The study is based on a literature review of available scientific articles and unpublished reports, and dependent on the availability of relevant resources. Therefore, the study is limited to analysis of what was extracted from the literature and the author's experience while 


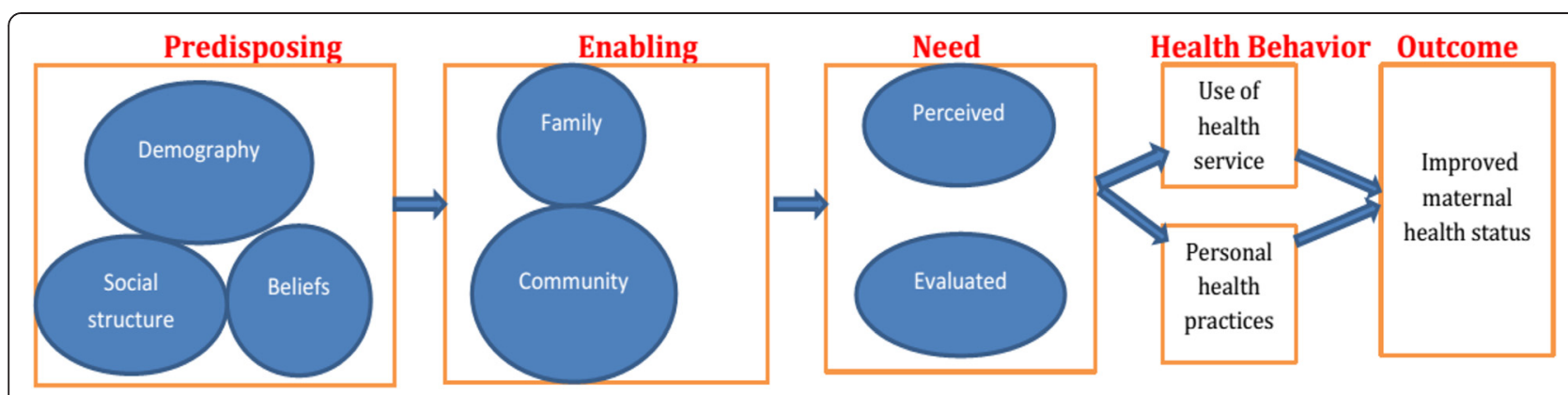

Figure 3 Adapted conceptual framework of the study explaining utilization of maternal health care services (Andersen 1995a)

working in Sudan on maternal health care projects.

- Some of the data are limited and/or out of date.

- Some of the data used in the study for rural areas are regarded as proxy indicators of the nomads' maternal health status.

\section{Findings}

Maternal health status and utilization of services

With an MMR of 360 maternal deaths per 100,000 live births, Sudan is ranked as one of the countries with the highest maternal mortality in the world. For every maternal death, 20 women or more may develop delivery- or birth-related complications or disabilities (Abdel-Tawab and El Rabbat 2010). Direct causes of maternal death in Sudan are the same as in other subSaharan countries, including haemorrhage, eclampsia, sepsis, unsafe abortion and obstructed labour (WHO et al. 2014; Ahmed et al. 2012). The major indirect causes are anaemia, malaria and hepatitis (Dafallah et al. 2003; Ahmed et al. 2012). Sudan's census shows that the MMR among nomads is very high, at 503 maternal deaths per 100,000 live births, with regional disparities. The highest values of MMR are reported in the western part of the country (Darfur and Kordofan) (Ahmed and Abdel-Rahman 2008). The high MMR among nomads suggests gaps in accessing goodquality maternal health care services and poor health practices.

Three quarters $(74 \%)$ of pregnant women undertake one antenatal care (ANC) visit, while $47 \%$ undertake four visits. This may be an indication of a low quality of service from the clients' perspective (Federal Ministry of Health 2011). Utilization of ANC services in Sudan is influenced by a number of factors. The mothers' level of education has a direct positive relation with utilization of the services, and utilization of ANC in urban areas is five times higher than that in rural areas (Ibnouf et al. 2007). The distance to health facilities and perceived quality of ANC also contribute to the utilization of services (Ali et al. 2010; Ibnouf et al. 2007). The Sudan
Household Survey (SHHS) shows a very low proportion of institutional delivery (20\%). This is because Sudanese culture encourages delivery at home in the presence of a trained midwife or traditional birth attendant (TBA), rather than facility-based delivery (Mohamed and Boctor 2009). Sudanese women perceive delivery at health facilities as meaning that they are unable to deliver normally. Delivery at home, where there is no means of reliable transportation, may lead to maternal death in cases of emergency; furthermore, obstructed labour during home delivery is a known cause of fistula in Sudan (Mohamed and Boctor 2009; Khalil 2011).

Obstetric fistula is a serious, devastating and humiliating condition that results from prolonged labour (WHO 2014b; Mohamed and Boctor 2009). In the majority of cases, fistula develops because the delivery is conducted at home and attended by unskilled personnel (Mohamed and Boctor 2009). In Sudan, almost half of fistula cases are in the western part of the country, where the majority of nomads live (Mohamed and Boctor 2009; Khalil 2011). The development of fistula is influenced by sociocultural factors such as FGM, early teen pregnancy, low level of education, poverty, malnutrition and a poor health system (Mohamed and Boctor 2009; Khalil 2011; WHO 2014b).

Findings from the 2010 SHHS reveal poor family planning indicators. The survey indicated that only $9 \%$ of women used family planning methods, and the unmet need for contraceptive was $29 \%$ (Federal Ministry of Health 2011). A review of literature (Ali and Okud 2013; Ahmed 2013; Brair and Eltayeb 2013) reveals that utilization of family planning in Sudan is influenced by many factors, with the level of education of women and their husbands and religious beliefs the most influential (Ali and Okud 2013). Women's low level of interest in family planning can be related to religious ideology; in Islamic countries, childbirth is always perceived as a natural practice. Therefore, the majority of Sudanese women consider family planning methods taboo (Serizawa et al. 2014). 


\section{Nomads' cultural practices and health needs}

The so-called life cycle approach is a tool developed to understand sexual and reproductive health concerns during human life cycles (Cohen and Burger 2000). The tool can be applied to the maternal health of nomads in Sudan, as a continuum from childhood to adulthood. As Figure 4 shows, during childhood, FGM is commonly practised in Sudan, with the prevalence estimated at $88 \%$ of women aged 15 to 49 (UNFPA and UNICEF 2013). Prevalence varies between states (Figure 5) and is almost the same in rural and urban areas and among different socio-economic quintiles. FGM is a violation of a child's rights and adversely affects her well-being (WHO 2012a; UNICEF 2010). Evidence from a study conducted by WHO revealed that women who undergo FGM are at higher risk of developing delivery consequences for both the mother and the baby (WHO 2012a).

In addition to FGM, adolescent girls are considered suitable for marriage; the mean age for marriage of females is 19 years and for males is 24 years (Ahmed and Abdel-Rahman 2008). The proportion of females who marry between the ages of 12 and 14 years is $5.8 \%$ (Table 2) and that between 15 and 19 years is $34 \%$. Almost two thirds of females between 20 and 24 years old are married. Early marriage is a maternal health concern because it is linked with adolescent/teen pregnancy (WHO 2014c). Teen pregnancy is known as a leading cause of death in adolescence because of delivery and birth complications.

In general, health needs are determined by the level of awareness and related to other factors such as gender, culture and tradition. Findings from a study by Serizawa et al. (2014) show that the perceived health needs of women in rural Sudan are strongly influenced by religion and beliefs. Sudanese women are like other Muslim women elsewhere in the world, with fatalistic beliefs with regard to health and well-being (Serizawa et al. 2014; Hedayat 2006). Interestingly, Sudanese women perceive ANC as a curative rather than a preventive measure (Serizawa et al. 2014; Furuta and Mori 2008). Moreover, the health needs of nomads are strongly influenced by gender norms, as access to information and health care services is largely controlled by men (Hampshire 2002). However, home remedies and treatment of reproductive health illnesses are considered women's responsibilities. For the most part, men do control the resources and are the decision-makers; therefore, access to health care information and services lies with men and their willingness to provide it. Men in nomadic society believe that reproductive health needs are better treated at home and with other females. Women may feel ashamed or embarrassed to discuss their health needs with their husbands and ask for their help.

\section{Enabling factors}

In general, nomads can afford the cost of health care, as evidenced by the fact that they contribute almost $60 \%$ of Sudanese Gross Domestic Product (GDP). In addition, $90 \%$ of livestock in Sudan are held by nomads (Smith et al. 2012; Ahmed and Abdel-Rahman 2008). Women in these nomadic communities are economically active, as they are allowed to own small groups of animals such as sheep and goats, are responsible for milking and selling surplus milk and can cultivate small areas of lands (Al Massar Charity Organization for Nomads Development 2003). Women use the income generated from these activities to purchase personal items or invest in other small income-generating activities.

Nomads' seasonal movement affects their utilization of health care services, as they might move nearer to or further away from existing services. Nomads in Sudan can move long distances with their livestock, searching for water and pasture. The movement and distribution of nomads in Sudan is influenced by a number of either environmental or human-related factors that determine their location: i) seasonal shortage of water; ii) density of biting flies; iii) a lack of salt in sand soil; and iv) the culture of the population (Weibel et al. 2008). The western

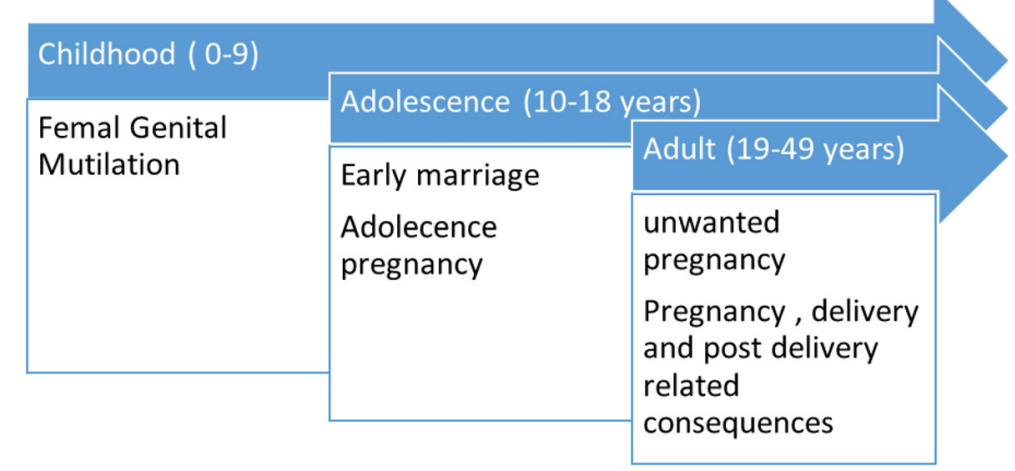

Figure 4 Maternal health care issues during the life cycle (Cohen and Burger 2000) 


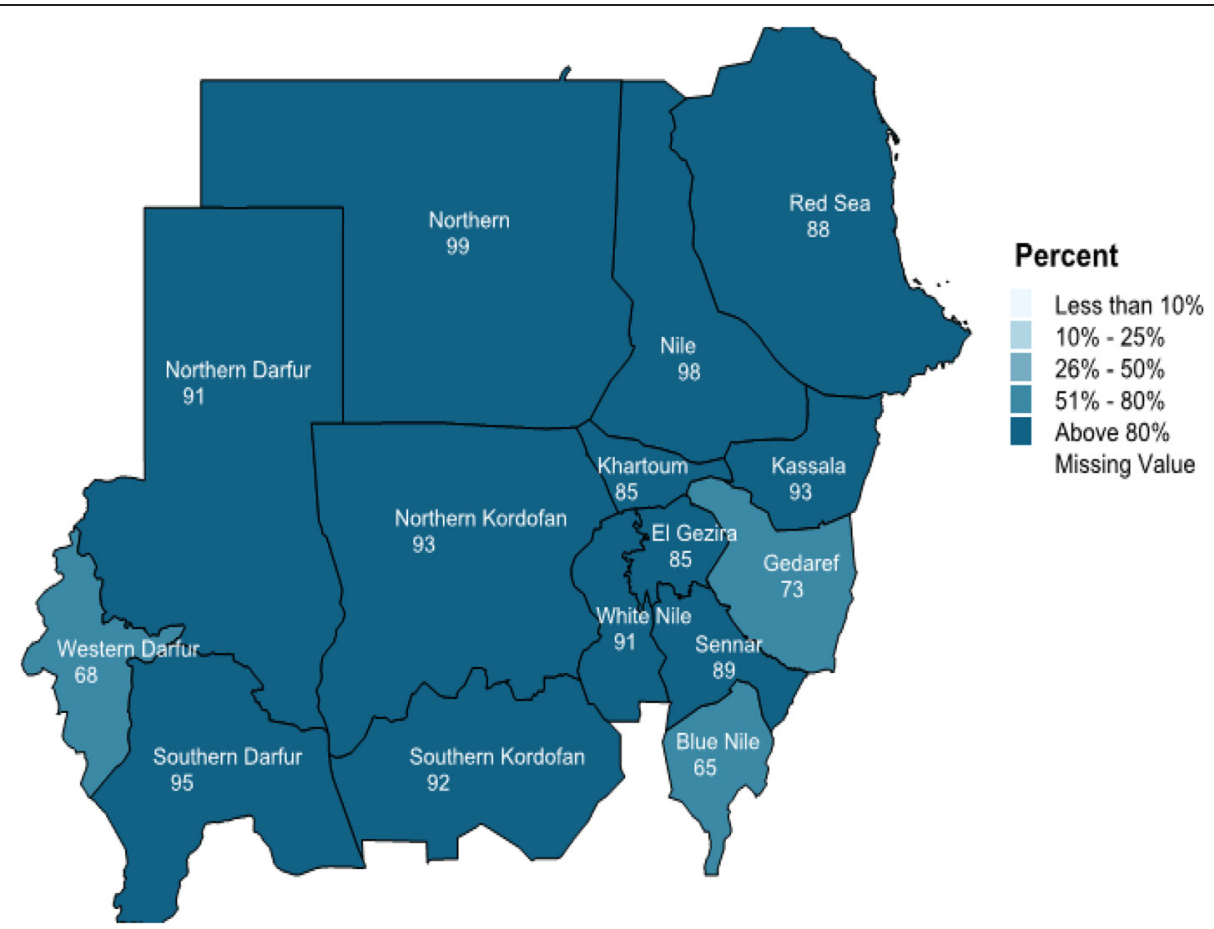

Figure 5 Geographical distribution of FGM in Sudan, 2010 (UNFPA and UNICEF 2013)

part of Sudan, where the majority of nomads are found, has undergone civil war and unrest for a long time, which has adversely affected the availability of health care services (Assal 2009).

The mobility of nomads acts as a protective factor against worm infestations and waterborne diseases such as cholera and hepatitis (Mocellin and Foggin 2008). This regular movement and the low population density also reduce risks of epidemic outbreaks. However, nomads can propagate an epidemic from one area to another (Schelling et al. 2005). Nomads have a better nutritional status than farmers, as nomads have a high milk diet and supplemented food practices (Schelling et al. 2005).

On the other hand, nomads are at risk of and susceptible to a wide range of illnesses and infectious diseases such as treponemal infection, brucellosis, measles, respiratory infections and diarrhoeal problems. This susceptibility and vulnerability is due to risky cultural practices such as i) their proximity to livestock, which is

Table 2 Proportion of early marriage among nomads, 2008 (Omer et al. 2008)

\begin{tabular}{lcl}
\hline Age & Percentage & \\
\cline { 2 - 3 } group & Male & Female \\
\hline 12 to 14 & 1.2 & 5.8 \\
15 to 19 & 5.7 & 34 \\
20 to 24 & 28.8 & 68.2 \\
\hline
\end{tabular}

a risk for the transmission of zoonotic diseases; ii) dietary practices such as drinking raw milk; iii) the nomads' perception of their health needs and health-seeking behaviour, which includes traditional healers; iv) their risky living environment, including poor housing conditions; and $v$ ) their frequent mobility and difficulty in accessing and utilizing health care services (Mocellin and Foggin 2008; Schelling et al. 2005).

\section{Predisposing characteristics}

Evidence from studies in other developing countries reveals a positive correlation between formal education and maternal health (McAlister and Baskett 2006). Women's level of education is directly associated with better utilization of health care services. The literacy rate is very low among the nomadic community: $80 \%$ of women and $75 \%$ of men are illiterate (Omer et al. 2009).

Gender relations are defined by different roles and responsibilities assigned by society to men and women (Ostlin et al. 2006). The traditions and cultures delineate tasks and responsibilities of individuals within nomadic society, and sketch the roles of women within the family and community. Gender norms affect maternal health through harmful traditional practices such as early marriage and FGM. They are always related to the community's beliefs and values. The majority of nomadic females (68 \%) are engaged in unpaid family work, and $15 \%$ work on their own account (Adam and Babiker 2009). Decision-making among nomads in regard to 
seeking health care is similar to other communities in developing countries. In general, women lack autonomy in health care decision-making (Herschderfer et al. 2012). The decision is always made by their husbands, as they control the resources, and the women usually seek permission before accessing health care services.

\section{Beliefs, values and attitudes}

The use of traditional and alternative medicine among Sudanese people is well contextualized by Dr. Tigani El Mahi, who stated that 'the belief in supreme beings or supernatural existence is widely accepted by Sudanese, not only among illiterate but also among well educated people' (Mohammed and Babikir 2013).

Literature shows that in rural areas of Sudan the common cultural practice is to use self-care or home remedies or to consult traditional healers. The general population perceives religious healers called Wali, Fagir or Shiekh as holy persons with extraordinary powers to cure ailments through prayers, charms and summons (Mohammed and Babikir 2013). Religious leaders have always played a significant role, which directly or indirectly influences maternal health. As mentioned above, certain traditions such as FGM and early marriage are practised for cultural and/or religious reasons. Decisionmaking about seeking care for maternal health problems falls under the domain of women, but they are influenced by husbands and religious leaders (Haile 2012).

\section{Nomadic best practices from other countries}

Community-based integrated primary health care interventions have been proved as an effective and efficient way to reduce maternal deaths and improve utilization of maternal health care services in Ethiopia (Ergano et al. 2012; Dynes et al. 2013). The Government of Ethiopia has adopted an approach called the 'health extension programme' (HEP) to provide services in pastoral areas (Ergano et al. 2012; Umer 2012; Dynes et al. 2013). The main goal of this approach is to prevent maternal mortality and morbidity among pastoralists by enhancing equitable access to community-based promotive, preventive and selected curative health care interventions (Ergano et al. 2012). Evidence found by Darmstadt et al. (2009) shows that use of trained community health workers (CHWs) has effectively reduced maternal mortality. In addition, Banteyerga (2011) and Ergano et al. (2012) have evaluated the impact of the HEP in relation to the utilization of maternal health care services in pastoral areas of Ethiopia. They reported that the coverage of ANC services, tetanus immunization and use of family planning had increasingly improved after the introduction of health extension workers (Ergano et al. 2012; Banteyerga 2011). Improvements in maternal health indicators can be attributed to the design of the health intervention, as it was aligned with the pastoralists' lifestyle, and the health extension workers were selected from nomadic communities (Umer 2012; Banteyerga 2011). The HEP indicates a positive impact on community health and shows that a community's health behaviour can be improved.

Delivery of health services through mobile clinics is recognized as the best way to provide care to continuously moving nomads. Mobile clinics have been observed to be more cost-effective than fixed facilities (Zinsstag et al. 2006). The utilization of maternal health care services is influenced by the nomads' perception of their health needs and the preference for the informal health system. Findings in the literature from studies conducted in Chad show that a combination of human and animal health interventions is an effective way to improve nomads' health (Schelling et al. 2007; Montavon et al. 2013). The joint vaccination campaign for children and women beside livestock increased the coverage of vaccination of children and women. It was found that the cost was $15 \%$ lower than for separate campaigns (Schelling et al. 2005; Schelling et al. 2007).

New roles for TBAs: There is a critical shortage of skilled birth attendants in developing countries due to geographical, political and social reasons (Wilson et al. 2011). TBAs are regarded as an alternative to cover the shortage of skilled birth attendants and improve maternal and neonatal care. TBAs are feasible, socially acceptable and an available option for women in developing countries (Wilson et al. 2011). Evidence shows that training and support for TBAs can reduce maternal deaths in areas with low coverage of skilled birth attendants (Darmstadt et al. 2009; Sibley et al. 2007). The effective use of TBAs should incorporate training, linkage to health care services, continuous in-service training and skills development, access to clean delivery kits, resuscitation equipment and effective referral pathways (Sibley et al. 2007; Wilson et al. 2011).

Maternity or birth waiting homes (MWHs) have been efficiently managed to overcome geographical barriers and transport problems for women to access maternal health care services in rural and remote areas (Herschderfer et al. 2012; Lee et al. 2009). MWHs are often located near health care facilities, to enable women to access services before the initiation of labour and even to stay there until it is time to give birth (Lee et al. 2009). The construction and operating costs of the MWHs can be financed by the communities themselves, the government or any other donor. This intervention is used by developing countries such as Sierra Leone, Cuba, Malawi, Nigeria, Papua New Guinea and Zimbabwe to bridge the geographical gap by bringing women at risk closer to emergency care (Herschderfer et al. 2012; Lee et al. 2009). Although there is limited evidence on the effectiveness of this widespread use of MWHs, it is likely to reduce maternal deaths in regions with low access 
to health care services (Lee et al. 2009). Evidence from Ethiopia shows the programme's effectiveness in reducing maternal mortality (Gaym et al. 2012). On the other hand, other countries report challenges, such as the sometimes lengthy waiting time, women needing to bring a relative to support them, and logistical problems of some MWHs with, for example, kitchens (Lee et al. 2009).

\section{Discussion}

Although the causes of maternal death are well known, they represent only one small aspect of maternal health. In this study, findings show that the utilization of maternal health care services by nomads is determined by predisposing factors, enabling conditions and health needs. Figure 6 was developed by the author to summarize linkages and relations between previous findings. The figure critically analyses the utilization of maternal health care services by nomads from the perspectives of both demand and supply. The low rate of utilization of maternal health care service is always due to demand-side and/or supply-related factors. Demand concerns people's willingness and ability to pay for services based on their needs. Decision-making about utilizing services is influenced by the presence or absence of components of predisposing factors, enabling conditions and health needs. These factors have a key function to inspire people regarding whether to use formal health care services or traditional or spiritual healers' services. These factors closely interact and are linked with each other in several ways, although components of each factor are also interrelated and amplify each other.

On the other hand, the low utilization of maternal health care services subjects women to high risks that lead to unfavourable consequences and increase the likelihood of maternal morbidity, mortality and disability. The different components of predisposing factors are closely interlinked and interrelated. In nomadic communities, problems and issues related to maternal health can be seen as early as during childhood and adolescence. The practices of FGM, early marriage and teen pregnancy are extensively performed by nomads. FGM is practised by almost all nomads in all regions of Sudan. In addition to immediate serious or even fatal complications, FGM can risk maternal well-being later, as women become at greater risk of developing fistulae or birth complications that can lead to maternal death or

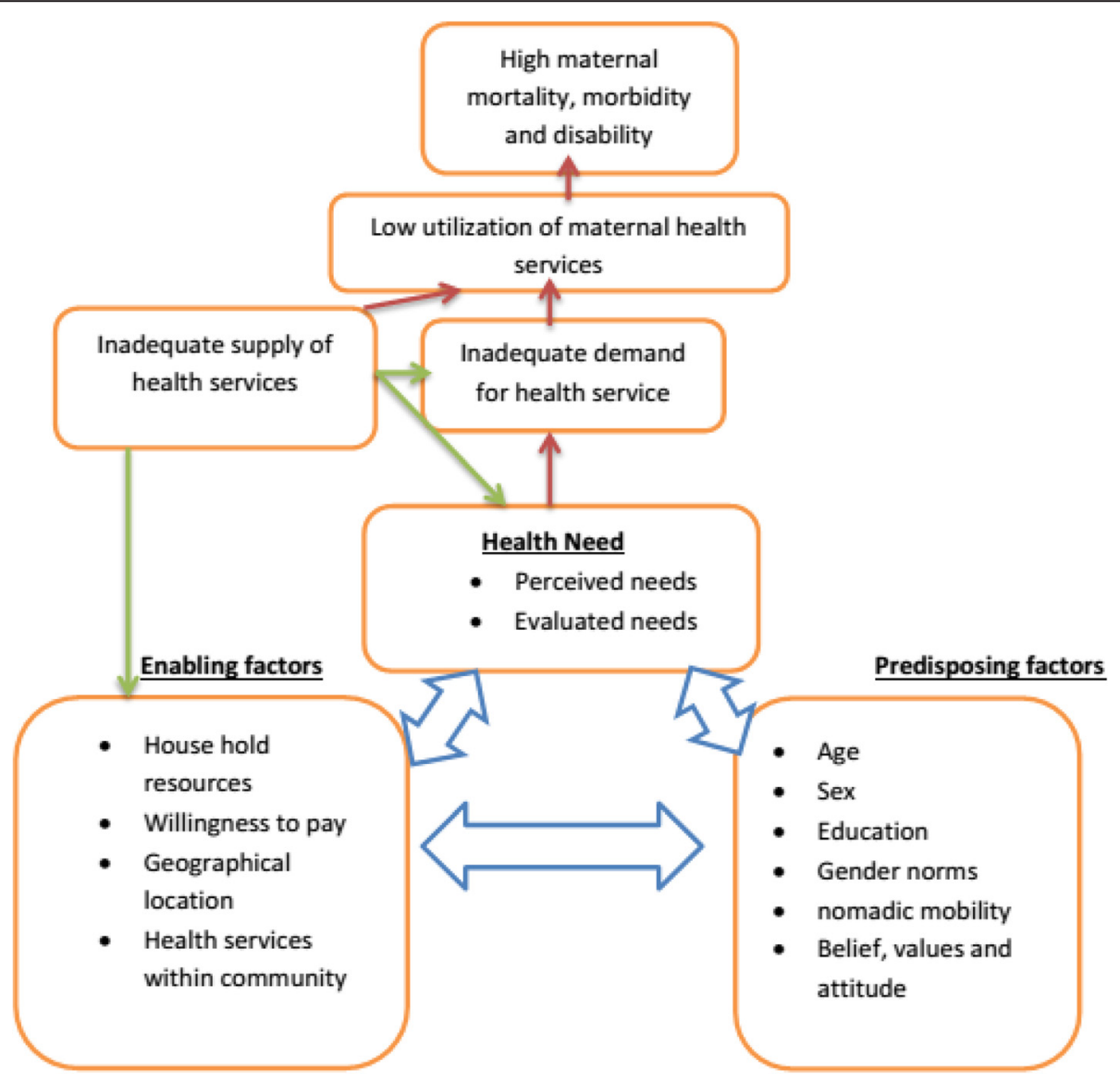

Figure 6 Interaction of predisposing factors, enabling factors, health need and utilization of maternal health care services 
disabilities. Besides FGM, early female marriage is widespread among nomadic society, as findings show that 34 $\%$ of girls aged less than 19 are married. Despite this, there are no data on teen pregnancy, but it is postulated to be high, based on the high prevalence of early female marriage and the high unmet need for family planning.

These harmful traditional practices are associated with low levels of education and of awareness about maternal and general health, which are other key characteristics of nomads. The roles of women in nomadic society are mainly reproductive, with some limited productive or economic activities. These ascribed roles and the position of women in society will sustain illiteracy among women and trap them in poverty. Although some nomadic women are economically active, they are still dependent on their men. As mentioned earlier, women perceive their husbands to be the decisive authority for consent to seek health advice and when and where to use health care services. The nomads perceive maternal health needs as women's issues; men are not involved, and it should be treated at home and by female kin. This misperception contributes to denying women access to maternal health care services.

Furthermore, the nomadic lifestyle and the physical environment are also significant predictors of maternal health. The regular movement of nomads acts as a barrier for women to access maternal health care services. The situation is even worse, as mobile facilities are not available to accompany the groups as they move. The distance to health facilities is another crucial factor. As mentioned before, nomads are concentrated in the western region of the country, where access to health facilities is limited for both nomads and settled communities. In fact, the current ongoing civil conflict in Darfur and some parts of Kordofan has negatively impacted maternal health (Kim et al. 2007).

The health-seeking behaviour of nomads is governed by individual beliefs, values and attitudes about health needs, similar to other population groups everywhere. Consultation of spiritual and traditional healers is widespread in Sudan. The utilization of informal health services is not always due to the absence of health facilities; it is also related to perceptions and beliefs. Decision-making about which services should be used is also influenced by tradition and the structure of the society; religious leaders play a significant role in manipulating people's perceptions and beliefs. The health-seeking behaviour of nomads needs to be explored further, as current data are severely limited.

The responsiveness of health services and health staff and the cost of the services are features of the health system that affect service utilization. Limited availability of health facilities in rural areas is a crucial factor for nomads' maternal health, especially the lack of emergency obstetric and neonatal care facilities. The shortage of key maternal health staff is another factor, as the national coverage of midwives (based on one midwife per village) is only 56 \% (Federal Ministry of Health 2010). This critical shortage of trained, skilled midwives will encourage people to continue to use the service of TBAs. Based on the author's observation and working experience, TBAs are popular among rural communities, especially among nomads, as the key maternal health care service provider, not only because of the shortage of trained village midwives but also because of traditional beliefs, the perceived quality of formal services and the cost of services. The unregulated work of TBAs can adversely impact maternal health, however. Thus, as the government is unable to supply the required number of skilled village midwives, TBAs can assume new roles as CHWs to reduce maternal morbidity and mortality.

Another factor related to health care services is their affordability. Although nomads in Sudan have income resources that can cover the cost of health care services, their willingness to pay remains a question that needs to be answered by further research and study. It is the author's hypothesis that the willingness to pay is linked to the gender norm, tradition, opportunity cost and level of education among nomads.

Nomads in Sudan are similar to those in nearby countries. The similarities include tradition, culture and attitudes. For example, FGM is widely practised among nomads in Ethiopia and Chad and the Masaai of Kenya. In addition, the nomads in these countries have the same socio-economic factors that permeate the practice of FGM, such as a low level of education, the popularity of FGM in rural areas, low healthfacility coverage and the same reasons for performing FGM. The prevalence of FGM is being reduced in these countries by implementing the same anti-FGM intervention. These similarities strongly suggest that the adaptation of best practices from other countries can improve the utilization of maternal health care services by nomads in Sudan.

As mentioned earlier, some interventions have been found effective in improving the utilization of maternal health care services. Community-based primary health care interventions such as the training and deployment of CHWs can improve maternal health. CHWs play an instrumental role in health care service delivery in rural and low-resource settings. CHWs differ from TBAs, as they seem to be younger, better educated and less bound to harmful traditional practices (Darmstadt et al. 2009). Evidence from the literature shows that CHWs can reduce the number of maternal deaths by educating women about a childbirth plan and a referral plan during childbirth, mobilizing their communities to use skilled birth attendants and providing delivery care for 
mothers and neonates (Hofmeyr et al. 2009; Lee et al. 2009).

Delivery of health care services through mobile clinics is the most effective approach for nomads. As nomads are continuously moving, mobile facilities are always the best approach for service delivery. Utilization of this service is influenced by nomads' health needs (Montavon et al. 2013; Schelling et al. 2007).

WHO (2012b) has excluded TBAs from its definition of skilled attendants and has banned them from service provision everywhere in the world. However, there is evidence about the effectiveness of training TBAs so that nomadic communities continue to trust them as service providers, just as other population groups in developing countries do (Wilson et al. 2011; Darmstadt et al. 2009; Sibley et al. 2007).

Another intervention that can improve nomadic maternal health is MWHs. This intervention can play a significant role in reducing maternal mortality by providing a safe place for women to stay near a health facility while her family moves to another area (Lee et al. 2009).

\section{Conclusion}

In conclusion, the utilization of maternal health care services by nomads in Sudan is extremely low. There are many factors influencing utilization; in general, they are the same as in other nomadic areas in Africa. They include individual characteristics such as age; children and adolescents are exposed to maternal health issues such as FGM, early marriage and teen pregnancy. Utilization of services is also affected by low levels of education and health awareness. The mobile lifestyle of nomads and gender inequality also act as major challenges that restrict women's utilization of maternal health care services. Although nomads can afford the cost of services, their willingness to pay cannot be judged. The limited availability of health facilities and health staff at the community level is a crucial factor that restricts nomadic women's access to health care services.

Finally, the utilization of health care services is influenced by nomads' perceived health needs, which are based on the beliefs, values and traditions that are central to the fabric of their society in Sudan.

\section{Recommendations}

Based on the findings and conclusions, the study recommends evidence-based strategies and interventions to improve the utilization of maternal health care services by nomads. The recommended strategies aim either to increase community demand for maternal health care services or bring women closer to emergency obstetric services. The following recommendations are proposed at policy, service-delivery and community levels:

\section{Policy level}

- The government should include nomadic CHWs and nomadic village midwives within existing human resources for health strategic policy and develop curricula for basic and in-service training programmes.

- The government should develop a national policy on the management and oversight of traditional medicine.

\section{Service-delivery level}

- State Ministries of Health should increase coverage of services for nomads by adopting the mobile-clinic approach.

- State Ministries of Health should train and deploy nomadic CHWs and nomadic village midwives to improve the utilization of maternal health care services.

- State Ministries of Health can adapt the MWH intervention to improve the utilization of maternal health care services.

- State Ministries of Health should sensitize and train health staff at fixed health facilities on nomads' special needs.

- State Ministries of Health should improve the quality of maternal health care services by improving the provision of essential equipment, instruments and supplies.

- State Ministries of Health should distribute human and financial resources equally between rural and urban areas.

\section{Community level}

- Social networks of nomadic women should be established to promote the utilization of services and empower women.

- Health awareness campaigns should be conducted at the community level to raise nomads' level of awareness about the importance of maternal health.

- An advocacy group comprising tribal, religious and community leaders should be established to advocate for better utilization of maternal health care services.

\section{Competing interests}

The authors declare that they have no competing interests.

\section{Authors' contributions}

BE has Prepared, designed and carried out the study and drafted the manuscript. AK gave advice on the scope and boundaries of the topic. Reading through drafts and gave feedback. Both authors read and approved the final manuscript. 


\section{Author details}

${ }^{1} J a b r a$ Taha Elmahi, Khartoum, Sudan. ${ }^{2}$ Royal Tropical Institute (KIT),

Amsterdam, The Netherlands.

Received: 1 June 2015 Accepted: 28 September 2015

Published online: 09 November 2015

\section{References}

Abdel-Tawab, N. and El Rabbat M. 2010. Maternal and neonatal health services in Sudan: Results of a situation analysis. Khartoum. Available at: http:// countryoffice.unfpa.org/sudan/drive/SudanPolicyBrief(Updated13042010).pdf. (2010 accessed at 12/5/2014).

Adam, E. and Babiker, M. 2009. Gender issues in Sudan. Khartoum. Available at: http://www.cbs.gov.sd/en/files.php?id=7\#\&panel1-2. Accessed 16 Feb 2014.

Ahmed, H. 2013. Barriers to family planning in Sudan: Results from a survey in White Nile, Kassala and Al-Gadarif, 2008. African Development Review 25(4): 499-512. Available at: http://doi.wiley.com/10.1111/1467-8268.12045. Accessed 8 Aug 2014

Ahmed, N. and Abdel-Rahman, N. 2008. Demographic and socio-economic characteristics of nomadic population/Sudan fifth census. Khartoum. (non-published report).

Ahmed, UT, Eltigani, L, Eltahir, S, \& Mirghani, SM. 2012. Maternal death review for maternal mortality reduction in Sudan 2010. Sudan Medical Journal 48(1): 13-23.

Al Massar Charity Organization for Nomads Development. 2003. Pastoralist baseline survey-Final report. Khartoum. (non-published report).

Ali, A. A. A., Osman, M. M., Abbaker, A. O., Adam, I. (2010). Use of antenatal care services in Kassala, eastern Sudan. BMC Pregnancy and Childbirth, 10(1), 67. doi:10.1186/1471-2393-10-67

Ali, AAA, and A Okud. 2013. Factors affecting unmet need for family planning in Eastern Sudan. BMC Public Health 13(1): 102. Available at: http:// www.biomedcentral.com/1471-2458/13/102. Accessed 20 July 2014

Ali, M.H. 2008. Evaluation and adjustment of the 2008 census data. Khartoum. Available at: http://www.cbs.gov.sd/en/files.php?id=7\#\&panel1-2. Accessed at 20/4/2014

Alnoory, MH. 2008. Maternal mortality analysis.. Available at: http:// www.cbs.gov.sd/en/files.php?id=7\#\&panel1-2. Accessed 16 Feb 2014

Andersen, R. 1995. Revisiting the behavioral model and access to medical care: Does it matter? Journal of Health and Social Behavior 36(1): 1-10. Available at: http://www.jstor.org/stable/2137284. Accessed 8 Aug 2014.

Anon. 2014. Geography of Sudan. In Wikipedia.. Available at: http://en.wikipedia.org/ wiki/Geography of Sudan\#Geographical regions. Accessed 19 Feb 2014.

Assal, M. 2009. The relationship between nomadic and sedentary people in Sudan in the context of State Policies and Internationalization. Nomadic Peoples 13(1): 154-170. Available at: http://www.ingentaconnect.com/content/whp/nomp/ 2009/00000013/00000001/art00009. Accessed 18 Feb 2014

Banteyerga, H. 2011. Ethiopia's health extension program: Improving health through community involvement. MEDICC Review 13(3): 46-49. Available at: http://www.scielosp.org/scielo.php?script=sci_arttext\&pid=S1555$79602011000300011 \&$ lng=en\&nrm=iso\&tlng=en. Accessed 8 Aug 2014.

Brair, S, and L Eltayeb. 2013. Barriers to family planning service utilization among Sudanese women in Khartoum locality, 2012. Available at: www.neelain.edu.sd/ assets/magazines/pdf/1/9/4.pdf. Accessed 8 Aug 2014

Casciarri, B, and AGM Ahmed. 2009. Pastoralists under pressure in present-day Sudan: An introduction. Nomadic Peoples 13(1): 10-22. Available at: http://www.jstor.org/ stable/43124143?seq=1\#page_scan_tab_contents. Accessed 10 Aug 2015.

Cohen, S, and M Burger. 2000. Partnering: A new approach to sexual and reproductive health. Available at: http://www.unfpa.org/webdav/site/global/shared/documents/ publications/2000/partnering_eng.pdf. Accessed 11 Aug 2014.

Dafallah, SE, FH El-Agib, and GO Bushra. 2003. Maternal mortality in a teaching hospital in Sudan. Saudi Medical Journal 24(4): 369-72. Available at: http:// www.ncbi.nlm.nih.gov/pubmed/12754536. Accessed 11 May 2014.

Darmstadt, GL, Lee, ACC, Cousens, S, Sibley, L, Bhutta, Z a, Donnay, F, Lawn, JE. 2009. 60 million non-facility births: Who can deliver in community settings to reduce intrapartum-related deaths? International Journal of Gynaecology and Obstetrics 107 Suppl(2009): S89-112. doi:10.1016/j.jjgo.2009.07.010 Available at: http:// www.pubmedcentral.nih.gov/ articlerender.fcgi?artid=3428830\&tool=pmcentrez\&rendertype=abstract Accessed 24 July 2014

Dynes, M, Buffington, ST, Carpenter, M, Handley, A, Kelley, M, Tadesse, L, Sibley, L. 2013. Strengthening maternal and newborn health in rural Ethiopia: Early results from frontline health worker community maternal and newborn health training.
Midwifery 29(3): 251-9. doi:10.1016/j.midw.2012.01.006 Available at: http:// www.sciencedirect.com/science/article/pii/S0266613812000071. Accessed 5 Aug 2014

Ergano, K, Getachew, M, Seyum, D, \& Negash, K. 2012. Determinants of community based maternal health care service utilization in South Omo pastoral areas of Ethiopia. Journal of Medicine and Medical Sciences 3(2): 112-121. Available at: amref.org/download/50b6291f0a06c/. Accessed 8 Aug 2014.

Federal Ministry of Health. 2011. Sudan household survey second round 2010 Summary report. Khartoum. Available at: http://reliefweb.int/report/sudan/sudanhousehold-and-health-survey-second-round-2010-summary-report. Accessed at 15/1/2014.

Federal Ministry of Health. 2010. National Strategy Document For Scaling-up Midwifery in the Republic of the Sudan. Khartoum. (non-published report).

Furuta, M, and R Mori. 2008. Factors affecting women's health-related behaviors and safe motherhood: A qualitative study from a refugee camp in eastern Sudan. Health Care for Women International 29(8): 884-905. Available at: http://www.tandfonline.com/doi/abs/10.1080/07399330802269600. Accessed 10 May 2014

Gaym, A, L Pearson, and KWW Soe. 2012. Maternity waiting homes in Ethiopia-Three decades experience. Ethiopian Medical Journal 50(3): 209-19. Available at: http://www.ncbi.nlm.nih.gov/pubmed/23409404. Accessed 11 Aug 2014

Haile, F. 2012. The influence of religious belief on maternal health in pastoralist communities in Afar region of Ethiopia. In Understanding nomadic realities, eds. A. Van Der Kwaak, et al., 45-47. Amsterdam: AMREF/KIT.

Hampshire, K. 2002. Networks of nomads: negotiating access to health resources among pastoralist women in Chad. Social Science \& Medicine 54(7): 1025-1037. Available at: http://www.sciencedirect.com/science/article/pii/ S0277953601000788. Accessed May 11, 2014

Hedayat, K. 2006. When the spirit leaves: Childhood death, grieving, and bereavement in Islam. Journal of Palliative Medicine 9(6): 1282-91. Available at: http://online.liebertpub.com/doi/abs/10.1089/jpm.2006.9.1282. Accessed 11 Aug, 2014

Herschderfer, K, Sam, E, Walker, P, Jalloh-Vos, H, Detmar, S, \& Koning, KD. 2012. Barriers and Promising Interventions for Improving Maternal and Newborn Health in Sierra Leone. Royal Tropical Institute (KIT).

Hofmeyr, GJ, Haws, RA, Bergström, S, Lee, ACC, Okong, P, Darmstadt, GL, Lawn, JE, et al. 2009. Obstetric care in low-resource settings: What, who, and how to overcome challenges to scale up? International Journal of Gynaecology and Obstetrics 107 Suppl: S21-44. S44-5. doi:10.1016/j.jjgo.2009.07.017 Available at: http://www.ncbi.nlm.nih.gov/pubmed/19815204. Accessed 20 July 2014.

Ibnouf, AH, HW van den Borne, and JA Maarse. 2007. Utilization of antenatal care services by Sudanese women in their reproductive age. Saudi Medical Journal 28(5): 737-43. Available at: http://www.ncbi.nlm.nih.gov/pubmed/ 17457442. accessed 10/2/2014

Khalil, A. 2011. A review of obstetric fistula in Sudan. Available at: http:// www.webmedcentral.com/article_view/2222. Accessed 8 Aug 2014.

Kim, G, R Torbay, and L Lawry. 2007. Basic health, women's health, and mental health among internally displaced persons in Nyala Province, South Darfur, Sudan. American Journal of Public Health 97(2): 353-61. Available at: http:// www.pubmedcentral.nih.gov/articlerender.fcgi?artid=1781379\&tool= pmcentrez\&rendertype=abstract. Accessed 3 Aug 2014.

Lee, ACC, Lawn, JE, Cousens, S, Kumar, V, Osrin, D, Bhutta, ZA, Darmstadt, GL. 2009. Linking families and facilities for care at birth: What works to avert intrapartumrelated deaths? International Journal of Gynaecology and Obstetrics 107 Suppl: S65-85. S86-8. doi:10.1016/j.ijgo.2009.07.012 Available at: http:// www.pubmedcentral.nih.gov/articlerender.fcgi?artid=3428847\&tool= pmcentrez\&rendertype=abstract. Accessed 20 July 2014.

Maro, G, Nguura, P, Umer, J, Gitimu, A, Haile, F, Kawai, D, Lukmay, K. 2012. Understanding nomadic realities- Case studies on sexual and reproductive health and rights in Eastern Africa. In, eds. A. Van Der Kwaak et al. Amsterdam: AMREF/KIT

McAlister, C, and T Baskett. 2006. Female education and maternal mortality: A worldwide survey. Journal of Obstetrics and Gynaecology Canada-Toronto 28(11): 983-90. Available at: http://www.ncbi.nlm.nih.gov/pubmed/17169224. Accessed 4 Aug 2014.

Mocellin, J, and P Foggin. 2008. Health status and geographic mobility among seminomadic pastoralists in Mongolia. Health \& Place 14(2): 228-242. Available at: http://www.ncbi.nlm.nih.gov/pubmed/17683967. Accessed 24 Feb 2014.

Mohamed, E, and M Boctor. 2009. Contributing factors of vesico-vaginal fistula (WF) among fistula patients in Dr. Abbo's National Fistula \& Urogynecology 
Centre-Khartoum 2008. Sudanese Journal of Public Health 4(2): 259-64. Available at: http://www.sjph.net.sd/files/vol4i2/SJPH-vol4i2-p259-264.pdf. Accessed 8 Aug 2014

Mohammed, I, and H Babikir. 2013. Traditional and spiritual medicine among Sudanese children with epilepsy. Sudanjp Org 13(1): 31-37. Available at: http://www.sudanjp.org/uploads/9/2/7/0/9270568/

2013_1_ora_traditional_and_spiritual_medicine_among_sudanese _children_with_epilepsy.pdf. Accessed 2 Aug 2014.

Montavon, A, Jean-Richard, V, Bechir, M, Daugla, DM, Abdoulaye, M, Bongo Naré, RN, Zinsstag, J. 2013. Health of mobile pastoralists in the Sahel - Assessment of 15 years of research and development. Tropical Medicine \& International Health 18(9): 1044-52. doi:10.1111/tmi.12147 Available at: http:// www.ncbi.nlm.nih.gov/pubmed/23834073. Accessed 31 Mar 2014.

Omer, S, Ahmed, N \& Osman, H, 2008. Gender Gap Analysis, Khartoum. (non- published report)

Omer, S, Ahmed, N, Osman, H. 2009. Gender gap analysis. Khartoum. (non-published report).

Ostlin, P, Eckermann, E, Mishra, US, Nkowane, M, \& Wallstam, E. 2006. Gender and health promotion: A multisectoral policy approach. Health Promotion International 21 Suppl 1(suppl_1): 25-35. doi:10.1093/heapro/dal048 Available at: http://heapro.oxfordjournals.org/content/21/suppl_1/25.short. Accessed 4 June 2014

Rosenstock, IM. 1974. Historical origins of the health belief model. Health Education \& Behavior 2(4): 328-335. Available at: http://heb.sagepub.com/ content/2/4/328.extract. Accessed 12 Aug 2014

Schelling, E, Bechir, M, Ahmed, MA, Wyss, K, Randolph, TF, \& Zinsstag, J. 2007. Human and animal vaccination delivery to remote nomadic families, Chad. Emerging Infectious Diseases 13(3): 373-9. doi:10.3201/eid1303.060391 Available at: http://www.pubmedcentral.nih.gov/ articlerender.fcgi?artid=2725911\&tool=pmcentrez\&rendertype=abstract. Accessed 11 Aug 2014

Schelling, E, Daoud, S, Daugla, DM, Diallo, P, Tanner, M, \& Zinsstag, J. 2005. Morbidity and nutrition patterns of three nomadic pastoralist communities of Chad. Acta Tropica 95(1): 16-25. doi:10.1016/j.actatropica.2005.03.006 Available at: http://www.sciencedirect.com/science/article/pii/ S0001706X05000902. Accessed 24 Feb 2014.

Schelling, E, C Diguimbaye, and S Daoud. 2003. Brucellosis and Q-fever seroprevalences of nomadic pastoralists and their livestock in Chad. Preventive Veterinary 61(4): 279-293. Available at: http://linkinghub.elsevier.com/retrieve/ pii/S0167587703002174. Accessed 24 Feb 2014

Serizawa, A, Ito, K, Algaddal, AH, \& Eltaybe, RAM. 2014. Cultural perceptions and health behaviors related to safe motherhood among village women in Eastern Sudan: Ethnographic study. International Journal of Nursing Studies 51(4): 572-81. doi:10.1016/j.jinurstu.2013.08.007 Available at: http:// www.journalofnursingstudies.com/article/S0020-7489(13)00247-2/abstract. Accessed 11 May 2014.

Sheikh, A, and J Velema. 1999. Where health care has no access: The nomadic populations of sub-Saharan Africa. Tropical Medicine \& International Health: TM \& IH 4(10): 695-707. Available at: http:// onlinelibrary.wiley.com/doi/10.1046/j.1365-3156.1999.00473.x/abstract. Accessed 11 May 2014

Sibley, LM, Sipe, TA, Brown, CM, Diallo, MM, McNatt, K, \& Habarta, N. 2007. Traditional birth attendant training for improving health behaviours and pregnancy outcomes. In L. M. Sibley (Ed.), Cochrane Database of Systematic Reviews. Chichester, UK: John Wiley \& Sons, Ltd. doi:10.1002/ 14651858.CD005460.pub2. http://www.who.int/entity/rhl/reviews/ CD005460.pdf.

Smith, M, Fadul, AJ, Tahir, AR, \& Akililu, Y. 2012. On the Hoof - Livestock Trade in Darfur. In On the Hoof - Livestock Trade in Darfur, 10-22. Nairobi: United Nation Environment Programme.

Sudan Central Bureau of Statistics. 2013. National accounts/National accounts indicators. Available at: http://www.cbs.gov.sd/en/files.php?id=4\#\&panel1-4. Accessed 12 Mar 2014.

Thaddeus, S, and D Maine. 1994. Too far to walk: Maternal mortality in context. Social Science \& Medicine 38(8): 1091-1110. Available at: http://www.sciencedirect.com/ science/article/pii/0277953694902267. Accessed 10 Jul 2014

Umer, J. 2012. The contribution of health extension workers in the formal maternal health care service in Afar, Ethiopia. In Understanding nomadic realities, eds. A. Kwaak et al, 67-71. Zowlle: AMREF/KIT.

UNDP. 2013. UNDP in Sudan - About Sudan. Available at: http://www.sd.undp.org/ content/sudan/en/home/countryinfo/. Accessed 5 Dec 2013
UNFPA and UNICEF. 2013. Joint evaluation of the UNFPA-UNICEF Joint Programme on Female Genital Mutilation/Cutting (FGM/C): Accelerating change (2008 - 2012). New York, NY. Available at: http://www.unicef.org/ evaluation/files/FGM-report_11_14_2013_Vol-I.pdf. accessed at 25/5/2014

UNICEF. 2010. The dynamics of social change towards the abandonment of female genital mutilation in five African countries. Citeseer. Available at: www.unicef-irc.org/publications/. Accessed 4 Jun 2014.

Weibel, D, Schelling, E, Bonfoh, B, Utzinger, J, Hattendorf, J, Abdoulaye, M Zinsstag, J. 2008. Demographic and health surveillance of mobile pastoralists in Chad: Integration of biometric fingerprint identification into a geographical information system. Geospatial Health 3(1): 113-124.

WHO. 2014a. Maternal mortality country profiles. Available at: http://www.who.int/ gho/maternal_health/countries/sdn.pdf?ua=1Q61. Accessed May 11, 2014

WHO. 2014b. Obstetric fistula: The untreated tragedy. Available at: http:// www.who.int/reproductivehealth/topics/maternal_perinatal/fistula-study/en/. Accessed 8 Aug 2014.

WHO. 2014c. Adolescents: Health risks and solutions. Available at: http:// www.who.int/mediacentre/factsheets/fs345/en/. Accessed 16 Jun 2014.

WHO. 2012a. Understanding and addressing violence against women: Female genital mutilation, vol. 1, 1-8. Available at: http://www.who.int/iris/handle/ 10665/77428. Accessed 4 Jun 2014

WHO. 2012b. WHO recommendations: Optimizing health worker roles to improve access to key maternal and newborn health interventions through task shifting. Geneva: WHO. Available at: http://www.popline.org/node/ 562104. Accessed at 28/6/2014.

World Health Organization. (2014). NHA indicators. Retrieved April 20, 2014, from http://apps.who.int/nha/database/DataExplorer.aspx?ws=0\&d=1.

Wilson, A, Gallos, I, Plana, N, \& Lissauer, D. 2011. Effectiveness of strategies incorporating training and support of traditional birth attendants on perinatal and maternal mortality: meta-analysis. BMJ 7102 (December 2011) 1-10. doi:10.1136/bmj.d7102.

Zinsstag, J, M Ould Taleb, and PS Craig. 2006. Editorial: Health of nomadic pastoralists: New approaches towards equity effectiveness. Tropical Medicine \& International Health: TM \& IH 11(5): 565-568. Available at: http:// www.ncbi.nlm.nih.gov/pubmed/16640607. Accessed 1 May 2014

\section{Submit your manuscript to a SpringerOpen ${ }^{\odot}$ journal and benefit from:}

- Convenient online submission

$\checkmark$ Rigorous peer review

- Immediate publication on acceptance

- Open access: articles freely available online

- High visibility within the field

- Retaining the copyright to your article

Submit your next manuscript at $>$ springeropen.com 